\title{
THE ROLE OF TECNOLOGICAL INNOVATION ON THE FIRM
}

\author{
Muzaffer ERTÜRK \\ Member of Internal Audit Board, IGDAS
}

\begin{abstract}
Technological innovation is the main factor affecting global competitiveness of the companies. The competitiveness and the profitability of the companies mainly depend on their ability of the technological innovation providing for the firm competitive advantage. This paper mainly investigates the role and importance of technological innovation in the firm level in order to analyse the technological determinants of the competitiveness and the profitability of the companies. The distinguished features of this study is to show that as long as technological innovation environment in the firm level improves, then the competitiveness and profitability of the firm increases.
\end{abstract}

Keywords: Technological Innovation Management, Firm Competitiveness

\section{INTRODUCTION}

The companies have to sustain their competitiveness in the increasing global competition conditions by introducing technological innovations. It is very important to find out the determinants of technological innovation in order to increase competitiveness of the firm. There are many factors affecting the technological innovation internal and external for the firms. In this study, it is mainly analysed the effects of technological innovation process and the effects of technological innovations on the competitiveness of the firm.

\section{The Importance of the \\ Technological Innovation for the Firm}

Technological innovation is the most important factor affecting the competitivennes of firm. Annavarjula, M. And Mohan, R. (2009) stated that in the era of globalisation and with the advent of knowledge economies, organisational innovation has assumed a critical role in enhancing economic performance of firms.

Knight (1967) stated that as a result of the rapid advances being made in science and technology innovation has become a key concept in today's society. Every industry and segment of Western society worries about the introduction of product improvements about production processes, and about organizational changes in their environment. Utterback (1971) stated that technological innovation has had an impact on international trade, industry structure, formation and development of new firms and industries, and the growth and the survival of existing firms and industries. This wide range of effects has been the focus of increasing discussion and interest. Hannay(1980) stated that technological change is one of the most fundamental and powerful forces affecting both the economy and society. National goals and public demands continue to set challenges for science and technology, particularly as goals and demands change. 
Damanpour, F., Bierly, Paul E. and Santoro, Michael D. (2009) stated that a firm's ability to acquire and exploit external knowledge is often critical to achieving and sustaining a competitive advantage. Their results show that predictors of exploration and exploitation of the application of external knowledge differ. Surprisingly, technological relatedness, -a common measure of absorptive capacity,- is negatively associated with the application of external knowledge to explorative innovations, indicating that knowledge from more distant sources is applied more to exploration. Their results also indicate that the effects of two external learning capabilities (prior experience with URCs and technological capability) on knowledge application are moderated in such a way by the tacitness of the knowledge transferred that experience is a stronger predictor when the knowledge is more explicit and technological capability is a stronger predictor when the knowledge is more tacit.

Huergo, Elena. (2006) stated that the determinants and the effects of successful innovations have become of great interest in recent years. This interest has been stimulated by two factors: the common perception of innovation as a basic element for economic growth and for the improvement of competitiveness in markets becoming increasingly global; and the increase of liberalization and reform of some industries that traditionally have been "public monopolies," like telecommunications and transport. This process, closely associated with technological change has promoted greater competition in these markets.

Narayanan (2001:121) stated that primary objective of technology management should be the creation of value for a firm. Value creation is tied to the competitive advantages that a firm can create in the marketplace or more precisely in the firm's competitive domains. Figure-1 shows the relationship between the technology and competitive advantage. Technology leads to both competitive dynamics and competitive advantage which leads to the value creation.

\section{Figure-1 Technology And Competitive Advantage}

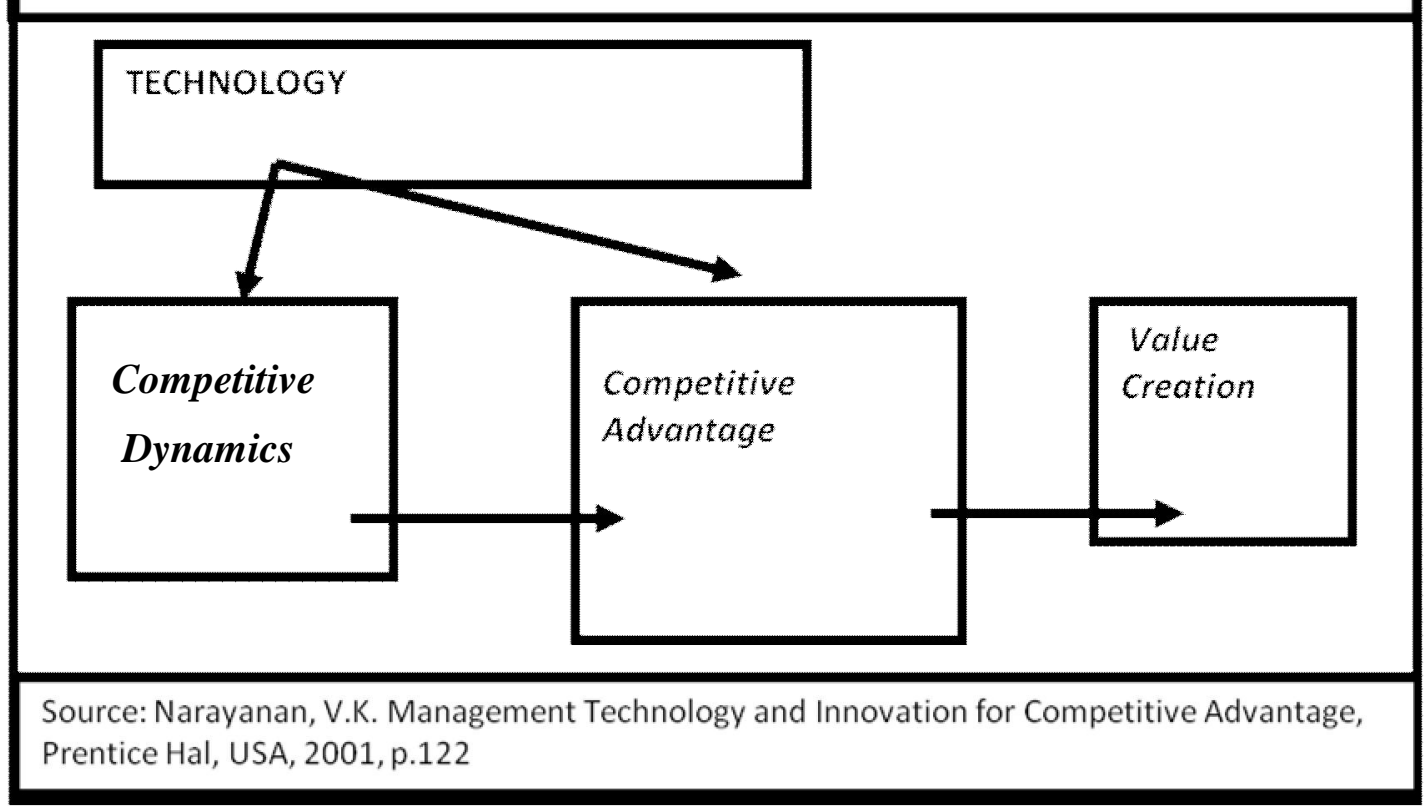

As the technology changes, new technologies abolish the old ones. Schilling (2008) stated that both the rate of a technology's performance improvement and the rate at which the technology is adopted in the marketplace repeatedly have been shown to conform to an S-Shape curve. Many technologies exhibit an S-Curve in their performance improvement over their lifetimes. When a technology's 
performance is plotted against the amount of effort and money invested in the technology, it typically shows slow initial improvement, and then followed by an accelerated improvement, then diminishing improvement. Performance improvement in the early stages of a technology is slow because the fundamental base of the technology are poorly understood. Figure-2 shows the Technology S-Curves, presenting that new technologies may have different characteristics, its effects on the old technologies and performance. In the early stages, efforts invested in a new technology may reap lower returns than efforts invested in the current technology, and firms are often reluctant to switch. However, if the disruptive technology has a steeper S-Curve (technology-2 in figure-2) or an s-curve that increases to a higher performance limit (technology-3 in figure-2), there may come a time when the returns to the effort invested in the new technology are much higher than the effort invested in the incumbent technology. New firms entering the industry are likely to choose the disruptive technology, and incumbent firms face the difficult choice of trying to extend the life of their current technology or investing in switching to the new technology. If the disruptive technology has much greater performance potential for a given amount of effort, in the long run it is likely to displace the incumbent technology, but the rate at which it does so can vary significantly.

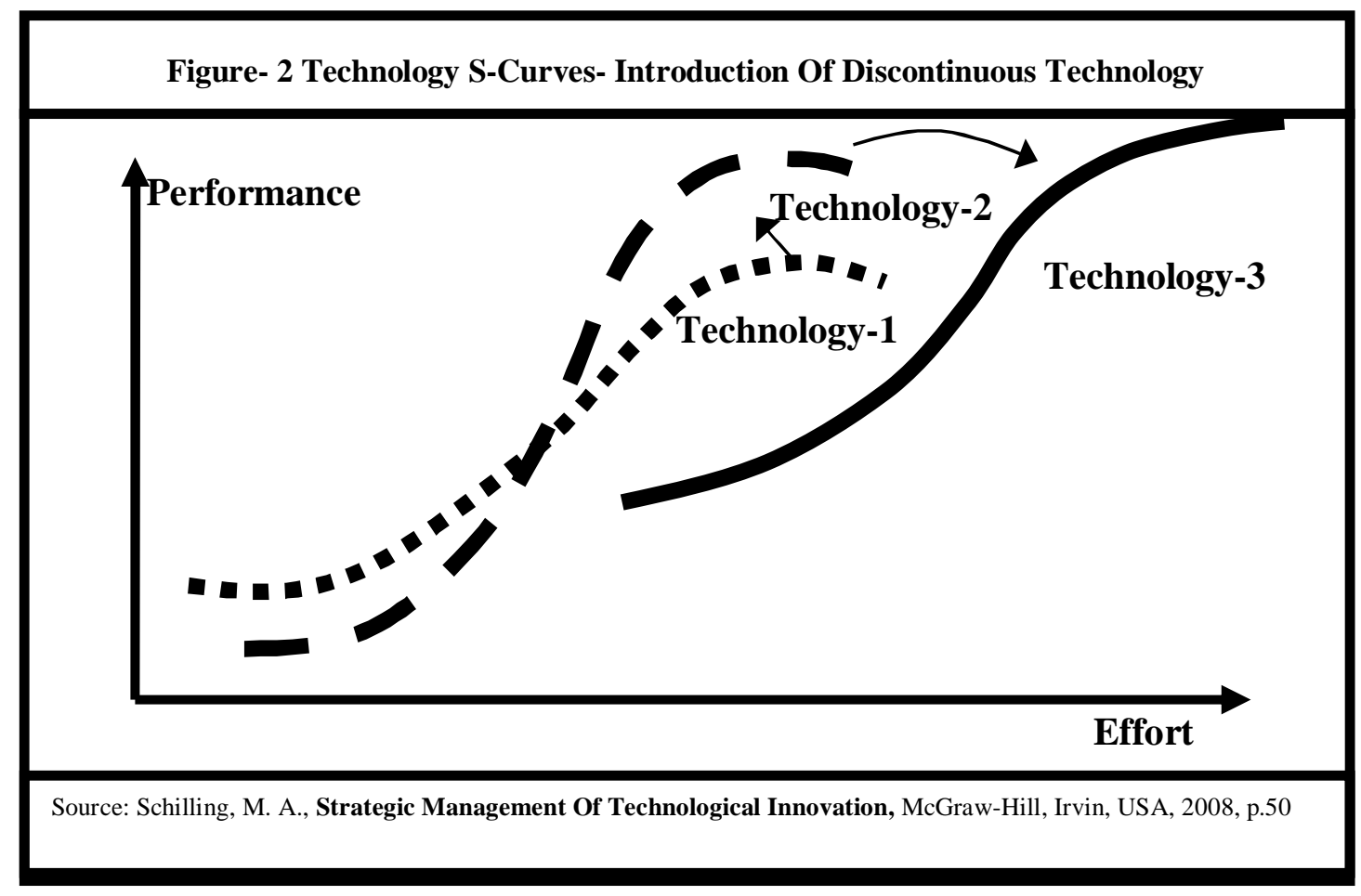

Technological change deeply affects the strategic investments decisions of the firms because of the competitiveness. Firms have to forecast technological change direction in order to allocate its resources to the investments which provide maximum profit. Annavarjula, M. And Mohan, R. (2009) utilised a broader definition of organisational innovation capability that includes the generation, dissemination and strength of innovative activity in a firm.

\section{Technological Innovation and Types}

Technological innovation basically presents the significantly improved technological novelty/change providing economic advantages for the firms. Technological innovation captures both technological invention and successful commercialization. 
Utterback (1971) stated that the invention is an original solution resulting from the synthesis of information about a need or want and information about the technical means with which the need or want may be met. An invention must be followed by entrepreneurial action before it has significance in economic terms. Thus, innovation will be defined to refer to an invention which has reached market introduction in the case of a new product, or first use in a production process, in the case of a process innovation. The key idea here is, that first use, does not preclude consideration of adopted ideas which are new in a particular market or application, nor does it provide a measure of the economic significance of an innovation. It simply requires that an idea has been carried far enough to begin to have an economic impact.

OECD and EuroStat (2005) stated that an innovation is the implementation of a new or significantly improved product (good or service), or process, a new marketing method, or a new organisational method inbusiness practices, workplace organisation or external relations. The minimum requirement for an innovation is that the product, process, marketing method or organisational method must be new (or significantly improved)to the firm. This includes products, processes and methods that firms are the first to develop and those that have been adopted from other firms or organisations.

Although technological innovation is so important for the firms' competitiveness in the global competitive environment, it is not easy to improve technological innovation for the firms. Technological innovation results from many efforts on $R \& D$, technological development processes and depends on the many factors affecting internal and external to the firms. OECD and EuroStat (1997) stated that it is important to distinguish between internal and external (or endogenous and exogenous) sources of change. Internally, interest is likely to focus on the role - or roles - of the R\&D department, and the involvement of all parts of the firm, particularly the marketing side, in decisions to innovate and on innovation activities. Externally, the focus will be on public research institutions as sources of technical information, and on inter-firm or inter-industry technology flows. Consideration of external sources of innovation or technological change ought logically to extend to international sources of technology, and be structured in such a way as to throw light on some of the unresolved problems with the technology balance of payments.

Utterback (1971) stated that the process of innovation will be considered as occurring in three overlapping phases or subprocesses, the first two of which culminate in an invention, and the last of which results in an innovation. These phases are: (1) idea generation, (2) problem solving, and (3) implementation, possibly followed by diffusion. The idea generation phase results in origination of a design concept or technical proposal, perhaps via synthesis of several pieces of existing information. The problem-solving phase results in an original technical solution, or an invention. The implementation phase results in market introduction of the original solution making it an innovation as defined above. Diffusion is the mechanism of communication and increasing use through which an innovation comes to have a significant economic impact.

OECD and EuroStat (2005) stated that the work of Joseph Schumpeter has greatly influenced theories of innovation. He argued that economic development is driven by innovation through a dynamic process in which new technologies replace the old, a process he labelled "creative destruction". In Schumpeter's view, "radical" innovations create major disruptive changes, whereas "incremental" innovations continuously advance the process of change. Schumpeter (1934) proposed a list of five types of innovations: i) Introduction of new products, ii) Introduction of new methods of 
production, iii) Opening of new markets, iv) Development of new sources of supply for raw materials or other inputs, v) Creation of new market structures in an industry.

OECD and EuroStat (2005) stated that four types of innovations are distinguished: product innovations, process innovations, marketing innovations and organisational innovations. Product innovations and process innovations are closely related to the concept of technological product innovation and technological process innovation. Marketing innovations and organisational innovations broaden the range of innovations.

Table-1 shows the classification of innovations; Narayanan (2001) stated that four major types of innovations in Table-1, incremental, modular, architectural and radical. Incremental innovation represents minor improvement or changes to the elements of an existing product or organizational technologies and practices. Modular innovation refers to significant changes in elements of products, organizational practices, and technologies without significant changes to the existing configuration of the elements. Architectural innovations use existing organizational practices and technologies but reconfigure them in new or different ways. Radical innovations represent revolutionary changes that require clear departures from existing organizational practices and technologies. Both process and product technologies can be classified into the four types of innovation enumerated in Table- 1 and Table-2.

Table- 1 Classification Of Innovations

\begin{tabular}{|c|c|c|c|}
\hline \multirow{2}{*}{$\begin{array}{c}\text { Characteristics } \\
\text { Of Elements: } \\
\text { Component Knowledge }\end{array}$} & $\begin{array}{l}\text { Minor } \\
\text { Change }\end{array}$ & Incremental & Architectural \\
\hline & $\begin{array}{l}\text { Novel } \\
\text { Change }\end{array}$ & Modular & Radical \\
\hline & & Existing & Novel \\
\hline & & \multicolumn{2}{|c|}{$\begin{array}{c}\text { Characteristics Of Linkage Among Elements : } \\
\text { Component Configuration }\end{array}$} \\
\hline
\end{tabular}

Table- 2 Classification Of Innovations ForProducts, Processes And Services

\begin{tabular}{|c|c|c|c|}
\hline & & \multicolumn{2}{|c|}{ Effect On Component Knowledge } \\
\hline & & Reinforced & Overturned \\
\hline \multirow{2}{*}{ 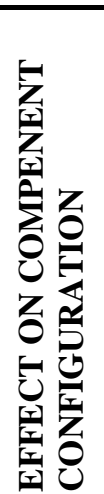 } & 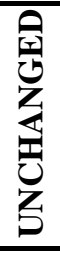 & $\begin{array}{c}\text { Incremental Innovations } \\
\text { Product Technology: } \\
486 \text { Microprocessors } \\
\text { Process technology : } \\
\text { Continuous Improvement } \\
\end{array}$ & $\begin{array}{c}\text { Modular innovations: } \\
\text { Product technology : } \\
\text { Digital phone } \\
\text { Process technology : } \\
\text { Quality Circles } \\
\end{array}$ \\
\hline & 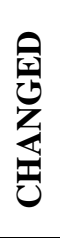 & $\begin{array}{l}\text { Architectural innovation : } \\
\text { Product technology : } \\
\text { Plain paper copiers } \\
\text { Process technology: } \\
\text { Just-in-time inventories }\end{array}$ & $\begin{array}{c}\text { Radical Innovations: } \\
\text { Product technologies: } \\
\text { VCR } \\
\text { Process technologies: } \\
\text { Robotics in Manufacturing }\end{array}$ \\
\hline
\end{tabular}


Fariborz, D.Richard M. W, Claudia N.A. (2009) stated that the impact of innovation on organizational performance depends on compositions of innovation types over time. They suggested that focus on adopting a specific type of innovation every year is detrimental, consistency in adopting the same composition of innovation types over the years has no effect, and divergence from the industry norm in adopting innovation types could possibly be beneficial to organizational performance.

\section{Technological Innovation Dynamics and Management}

Technological innovations have important dynamics to arise for the firms. It is important to apply important policies to trigger for the technological innovation both in firm and economy level. Edquist, Charles and Leif Hommen (1999) claimed that innovation policies can be classified as demand-side oriented or supply-side oriented. Similarly, theories of the innovation process can be classified as being linear or systems-oriented. There are important parallels and logical connections to be drawn between these two classifications. On the one hand, linear views of the innovation process support a supply-side orientation in innovation policies. On the other hand, systems perspectives on innovation yield a much more fruitful perspective on the demand side, in terms of both theoretical and policy relevance. Huergo, Elena, (2006) stated that the planning and monitoring of the innovation process and the hiring of personnel with special skills for technological activities are significant sources of innovation, although with important differences regarding the type of innovation (process versus product). In addition, the evidence suggests that large firms' advantages for the generation of product innovations are related to a different use and effectiveness of technological management mechanisms.

Figure-3 shows the interactive model of innovation capturing both market pull and technology push. According to the Figure-3, innovation results from both market pull capturing needs of the society and market. On the other hand technology push capturres the latest advances in science and technology.

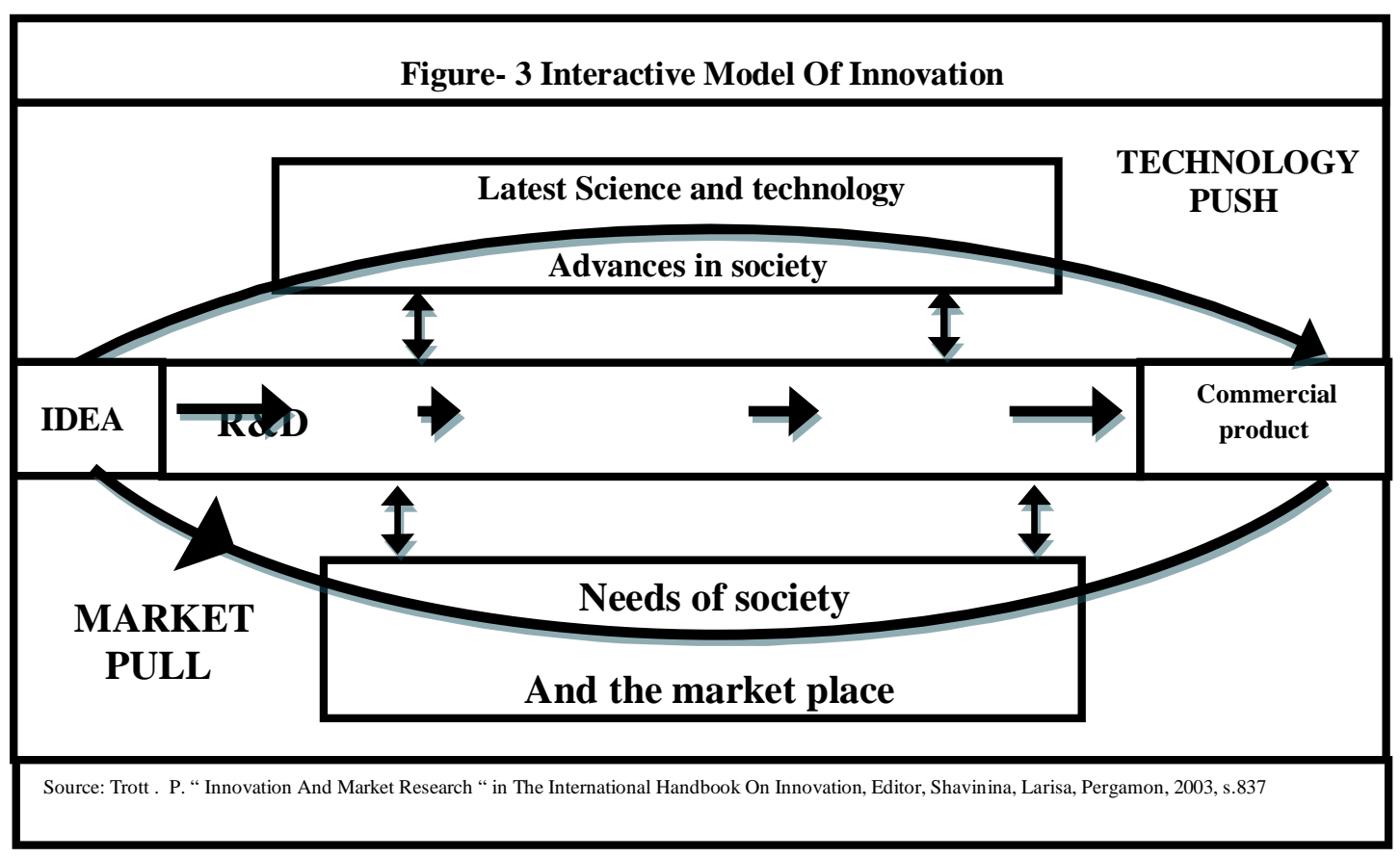


OECD and EuroStat (1997) stated that the technological capability of a firm depends on the structure of its labour force and facilities (skills, departments), its financial structure, its strategy on markets, competitors, alliances with other firms or with universities, and above all its internal organisation. Many of these aspects are complementary. A particular skill structure will go hand in hand with a particular type of strategy, financial structure and so on.

Galende and Fuente (2003) in Table-3 emphasized that a summary of the main theoretical arguments and empirical studies concerning the effect of internal factors on the innovative activity. It is easy to see that the traditional course of theoretical argument and of empirical contrast deals with the direct impact of the internal factors on a firm's innovative result.

\section{Table- 3 Internal Factors And Innovation}

\begin{tabular}{|c|c|c|}
\hline Factor & Theoretical & Empirical Studies \\
\hline \multirow[b]{2}{*}{ Size } & $\begin{array}{l}\text { Large: Economies, } \\
\text { Risk, Market, } \\
\text { Appropriation }\end{array}$ & $\begin{array}{l}\text { Large: Horowitz (1962), Lunn And Martin (1986), Braga And Will- } \\
\text { more } \\
\text { (1991), Henderson And Cockburn (1996), Gumbau (1997), Arundel }\end{array}$ \\
\hline & $\begin{array}{l}\text { Small: Flexibility, } \\
\text { Communication, } \\
\text { Specialisation, } \\
\text { Informal Controls }\end{array}$ & $\begin{array}{l}\text { Small: Worley (1961), Mansfield (1964), Grabowski (1968), Adams } \\
\text { (1970), Loeb And Lin (1977), Scherer (1984), Acs And Audretsch } \\
\text { (1988), Graves And Langowitz (1993) } \\
\text { Intermediate: Scherer (1965b), Mansfield Et Al. (1971), Smith } \\
\text { (1974), Kumar And Saqib (1996) Both: Rothwell (1986), Pavitt Et }\end{array}$ \\
\hline Debt & $\begin{array}{l}\text { Negative: Specificity, } \\
\text { Risk, } \\
\text { Information } \\
\text { Asymmetries }\end{array}$ & $\begin{array}{l}\text { Negative: Grabowski (1968), Elliott (1971), Branch (1974), Kamien } \\
\text { And Schwartz (1978), Hall (1990), Long And Ravenscraft (1993), } \\
\text { Giudici And Paleari (2000) }\end{array}$ \\
\hline Human Resources & $\begin{array}{l}\text { Positive: Qualifica- } \\
\text { tion, }\end{array}$ & $\begin{array}{l}\text { Positive: Galende And Su’Arez (1998, 1999), Mart'Inez-Ros And } \\
\text { Salas (1999) }\end{array}$ \\
\hline $\begin{array}{l}\text { Commercial Re- } \\
\text { sources }\end{array}$ & $\begin{array}{l}\text { Positive: Reputation, } \\
\text { Image, } \\
\text { Complementary } \\
\text { Resources, } \\
\text { Information }\end{array}$ & $\begin{array}{l}\text { Positive: Freeman (1973), Rothwell Et Al. (1974), Doi (1985), Lunn } \\
\text { And Martin (1986), Gumbau (1997) }\end{array}$ \\
\hline $\begin{array}{l}\text { Organisational Re- } \\
\text { sources }\end{array}$ & $\begin{array}{l}\text { Positive: } \\
\text { Co-Ordination, } \\
\text { Communication, } \\
\text { Integration, }\end{array}$ & $\begin{array}{l}\text { Positive: Freeman (1973), Rothwell Et Al. (1974), Rothwell (1986), } \\
\text { Kleinknecht And Reijnen (1992), Busom (1993), Bughin And } \\
\text { Jacques (1994), Kumar And Saqib (1996), Gumbau (1997), Kuem- } \\
\text { merle (1998) }\end{array}$ \\
\hline Diversification & $\begin{array}{l}\text { Negative: Formal And } \\
\text { Financial } \\
\text { Controls }\end{array}$ & $\begin{array}{l}\text { Positive: Mceachern And Romeo (1978), Link (1982), Chen (1996) } \\
\text { Negative: Hoskisson And Hitt (1988), Baysinger And Hoskisson } \\
\text { (1989), Hoskisson And Johnson (1992), Hoskisson Et Al. (1993) }\end{array}$ \\
\hline Internationalisation & $\begin{array}{l}\text { Positive: } \\
\text { Competitiveness, } \\
\text { Market } \\
\end{array}$ & $\begin{array}{l}\text { Positive: Meisel And Lin (1983), Lunn And Martin (1986), Braga } \\
\text { And Willmore (1991), Busom (1991), Labeaga And Mart Inez-Ros } \\
\text { (1994), Kumar and Saqib (1996), Galende and Su'arez (1998, 1999) }\end{array}$ \\
\hline \multicolumn{3}{|c|}{$\begin{array}{l}\text { Source : Galende A, Jesús, Juan Manuel De La Fuente, “Internal Factors Determining A Firm's Innovative Behaviour” } \\
\text { Research Policy } 32 \text { (2003) 715-736 }\end{array}$} \\
\hline
\end{tabular}

Galende and Fuente (2003) modelled internal determinants of the innovative process in Figure-4. They emphasized the confirmed hypotheses together with the innovative characteristic that has been used as a dependent variable. These relationships allow the following to be confirmed: The companies that opt for an internal method of technology generation have greater organisational resources. 
The internal sources of scientific and technological information are used by firms with greater organisational resources. These resources also induce an important use of external sources of information. The accumulative nature of the innovative activity, determined by the innovative age of the company, is increased by the firm's size, by the possession of greater organisational resources and by the firm's level of internationalisation. The objectives for the innovation related to the entry into new markets is more frequent in internationalised firms. Companies that invest a greater proportion of their R\&D activities in basic and applied research possess greater organisational resources. The generation of a greater proportion of product innovations is the characteristic of the companies with high commercial resources, and the intense development of incremental innovations is carried out by debt financing firms.

Figure- 4 Internal Determinants Of The Innovative Process

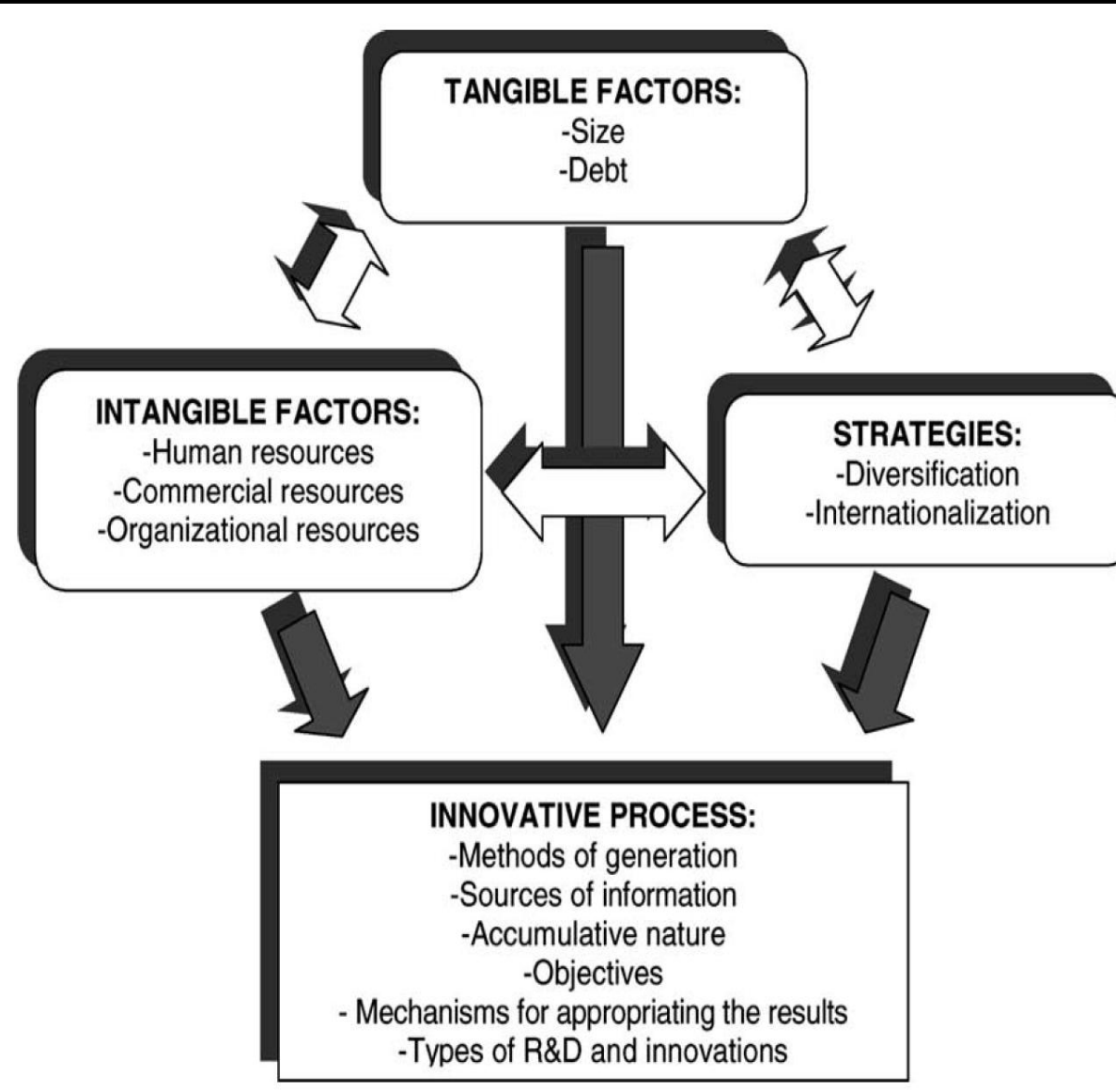

Source : Galende A, Jesús, Juan Manuel De La Fuente, “Internal Factors Determining A Firm's Innovative Behaviour" Research Policy 32 (2003) 715-736

Technological innovations, therefore technological management is very important for the firms. Narayanan (2001:8) stated that management of technology links engineering, science and management disciplines to plan, to develop, and to implement technological capabilities for the aim of shaping and accomplishing the strategic and operational goals of an organization. Three important dimensions of the definition are as that;

1-The emphasis in the management of technology is to accomplish the goals of an organization. 
2-Technology management focuses on the development of technological capability and its implementations or deployment in products and processes.

3-Technology management within corporations is linked to other management activities. Narayanan (2008:8) defined that management of technology (see in Figure-5) focuses on the principles of strategy and organization involved in technology choices, guided by the purpose of creating value for the investors. Narayanan stated that all management, including the management of technology start with some statement of a firm's identity and purpose. The answer to the question what is our business? Has been provided by two complementary perspectives: market based and resource based.

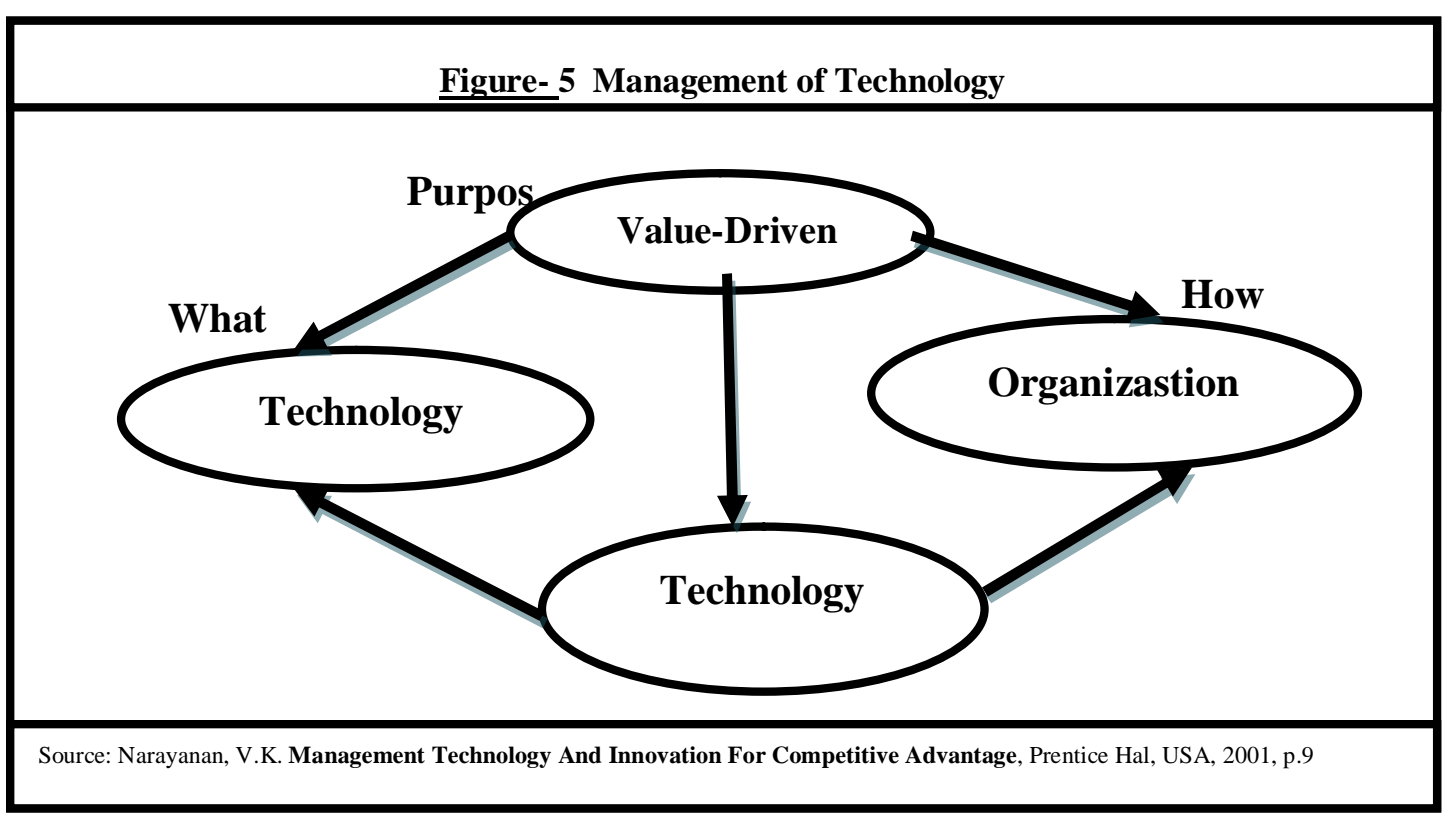

It is important for the firms to analyse the relationship among the product system, business system, technology system and application system in order to understand the relationship among profitability, sales\&market and technology push\&market push conditions. Figure- 6 shows product system as a linking system. The relationships among these systems deeply affect the profitability and competitiveness of the firms.

One of the most important factors affecting firms' competitiveness is technological new product development, in other words, technological innovations. Technological innovations are very important for the firms in order to increase the profitability and the competitiveness of the firms. Technological innovation development models vary from linear innovation models to cyclical innovation models. Betz (1993:25) stated that in contrast to the logic of a linear radical innovation process; proceeding from science to technology.

These models present the management of technological change dynamics to increase the competitiveness of the firm. Figure-7 shows cyclical innovation process. Betz (1993:25) stated that in contrast to the logic of a linear radical innovation process proceeding from science to technology, the logic of cyclic incremental innovation processes differs substantially, cyclical around technology and product. The logic of cyclic innovation process consists of five central concepts: 1- Technology anticipation,

2- Technology acquisition, 
3- Technology implementation,

4- Technology exploitation,

5- Technology stimulation. It is necessary to first anticipate technological change so that one has time to prepare and take advantage of it. Next, it is necessary to acquire new technology for use by the firm. Then new technology can be embedded into new products, processes or services. The next logical step is to commercially exploit the new technology through new product introductions and aggressive pricing/quality strategies. Customers' subsequent experiences with the new products suggest new needs and stimulate requirements for more new technology. The cyclic innovation process is driven by incremental improvements to technology that periodically improves the value of products to customers. For firms, these steps form a kind of circular pattern in the technical and business activities of the firm.

\section{Figure- 6 Product System As A Linking System}

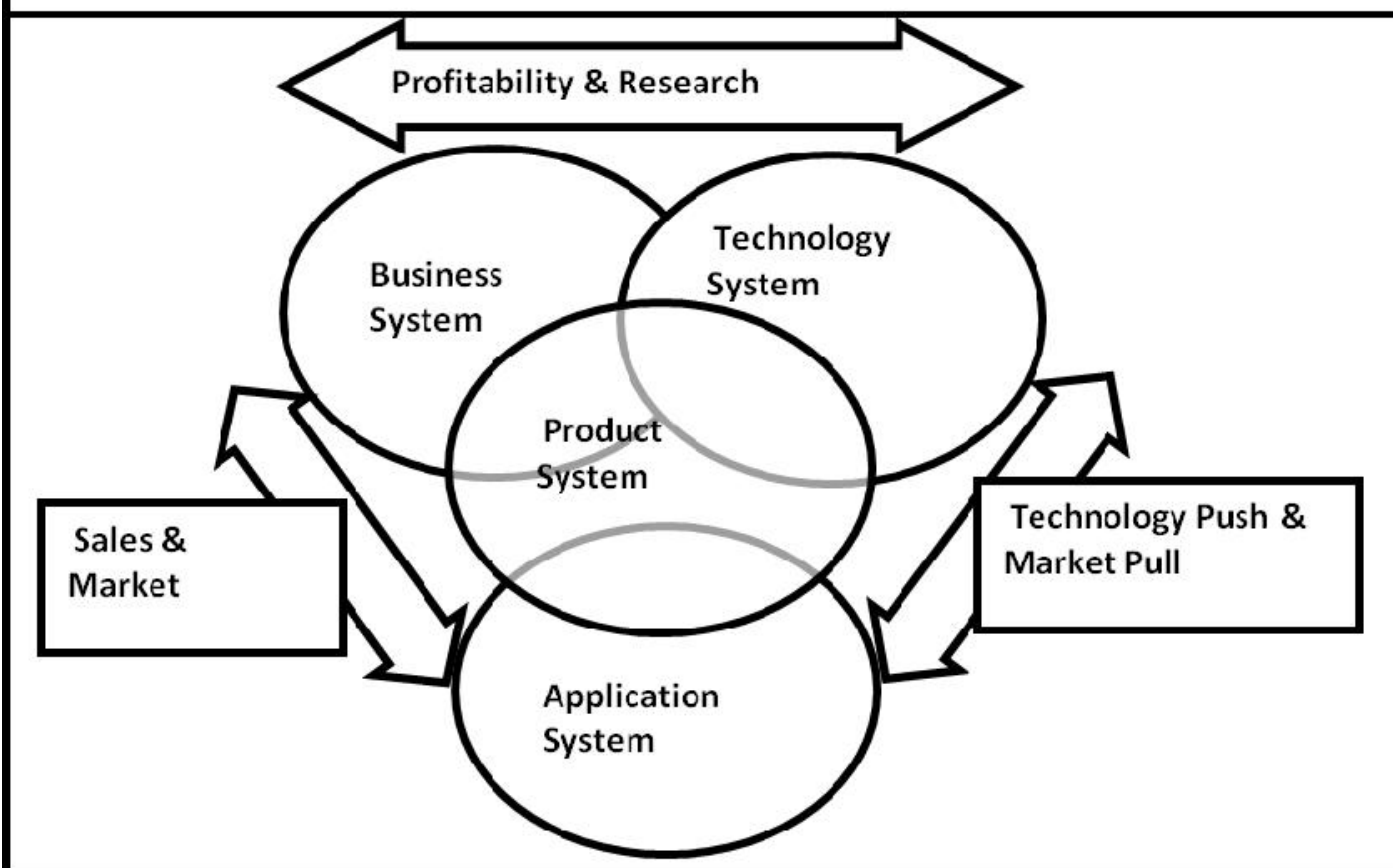

Source: Betz, F. Strategic Technology Management, Mcgraw-Hill, 1993, p.363

Betz (1993:26) stated that the linear radical innovation process provides dramatic, discontinuous impacts on the economy (enabling the creation of new markets or the entry of existing markets), whereas the cyclic incremental innovation process provides quiet, steady, continuous impacts on the economy (eventually enabling the capture and domination of markets). Figure- 8 shows integration cyclical innovation with linear innovation in next-generation technology product. In the cyclical innovation process, the stimulation of need for new technology fosters the vision of a next-generation technology in the linear innovation process. The technical feasibility prototype in the linear innovation process provides the grounds for anticipation of new technology in the cyclic innovation process. The functional prototype in the linear innovation process provides the information for acquiring new technology in the cyclic innovation process. The implementation phase in the cyclic innovation process designs the engineering prototype in the linear innovation process (which with concurrent engineering practice also fosters the manufacturing prototypes and pilot production). Volume pro- 


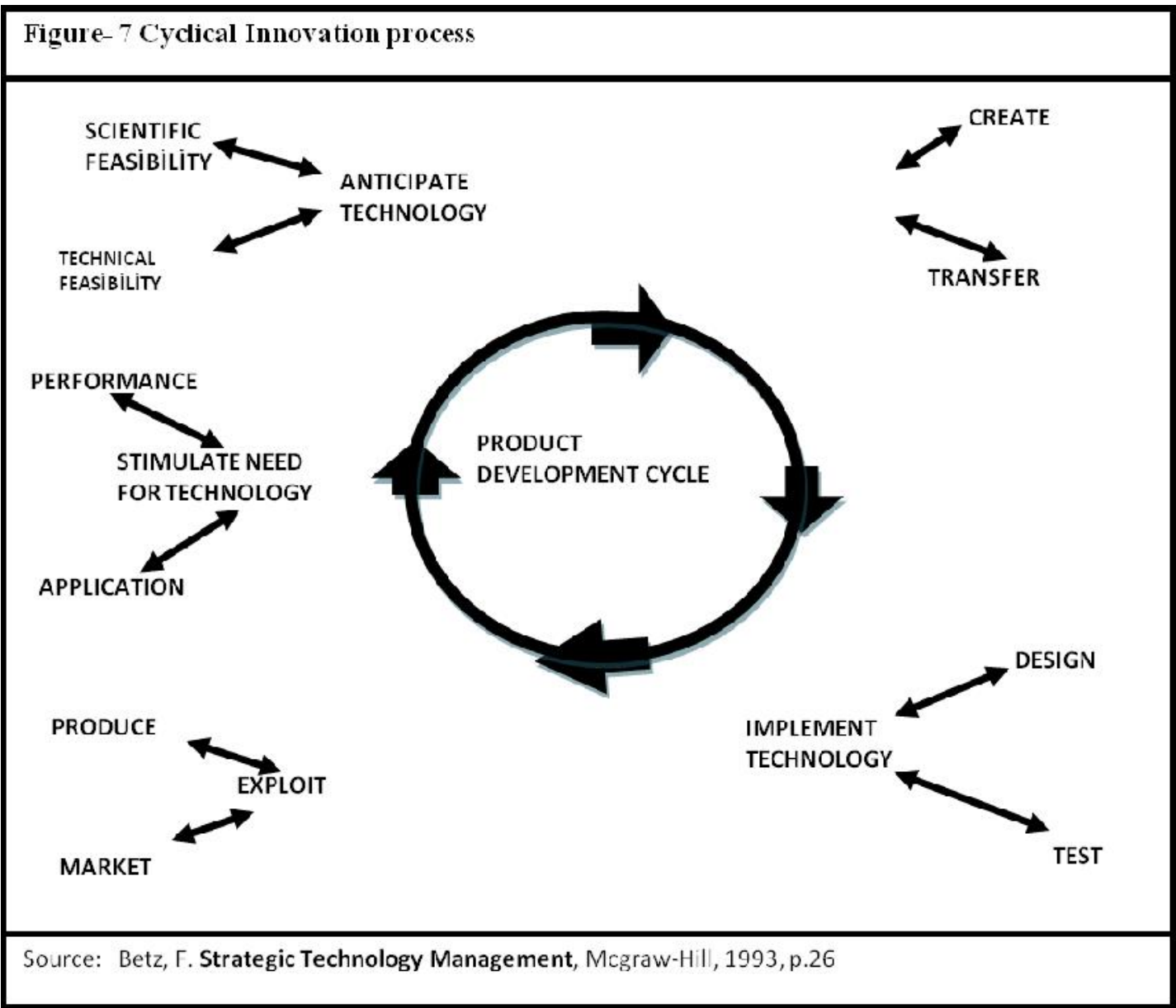

duction in the linear innovation process of the next-generation product provides the opportunity for exploitation of the new technology in the cyclic innovation process. By establishing "technical feasibility" the new linear innovation process can provide anticipation to the cyclic innovation process for the new generation of a technology.

Narayanan (2001:255) stated that technology strategy is the revealed pattern in the technology choices of firms. The choices involve the commitment of resources for the appropriation, maintenance, deployment, and abandonment of technology capabilities. These technology choices determine the character and extent of the firms' principal technical capabilities and the set of available product and process platforms. The important points of the definition are as follows:

1-Technology strategy focuses on the kinds of technologies that a firm selects for acquisition, development, deployment or deinvestment.

2-Commitments surrounding technology selection define technology strategies.

3-Technology strategies are not confined to high-technology industries. Even a capacity-driven industry or a customer-driven industry requires a technology strategy.

4-finally, technology strategies embrace both the hardware and software elements of a technology. Although the term technology is often associated with hardware elements, the preceding definition of technology strategy includes both software and hardware elements. On the other hand, Figure-9 shows the central principles of technology choices including firms' objective, drivers, decision criteria and choice outcomes. 


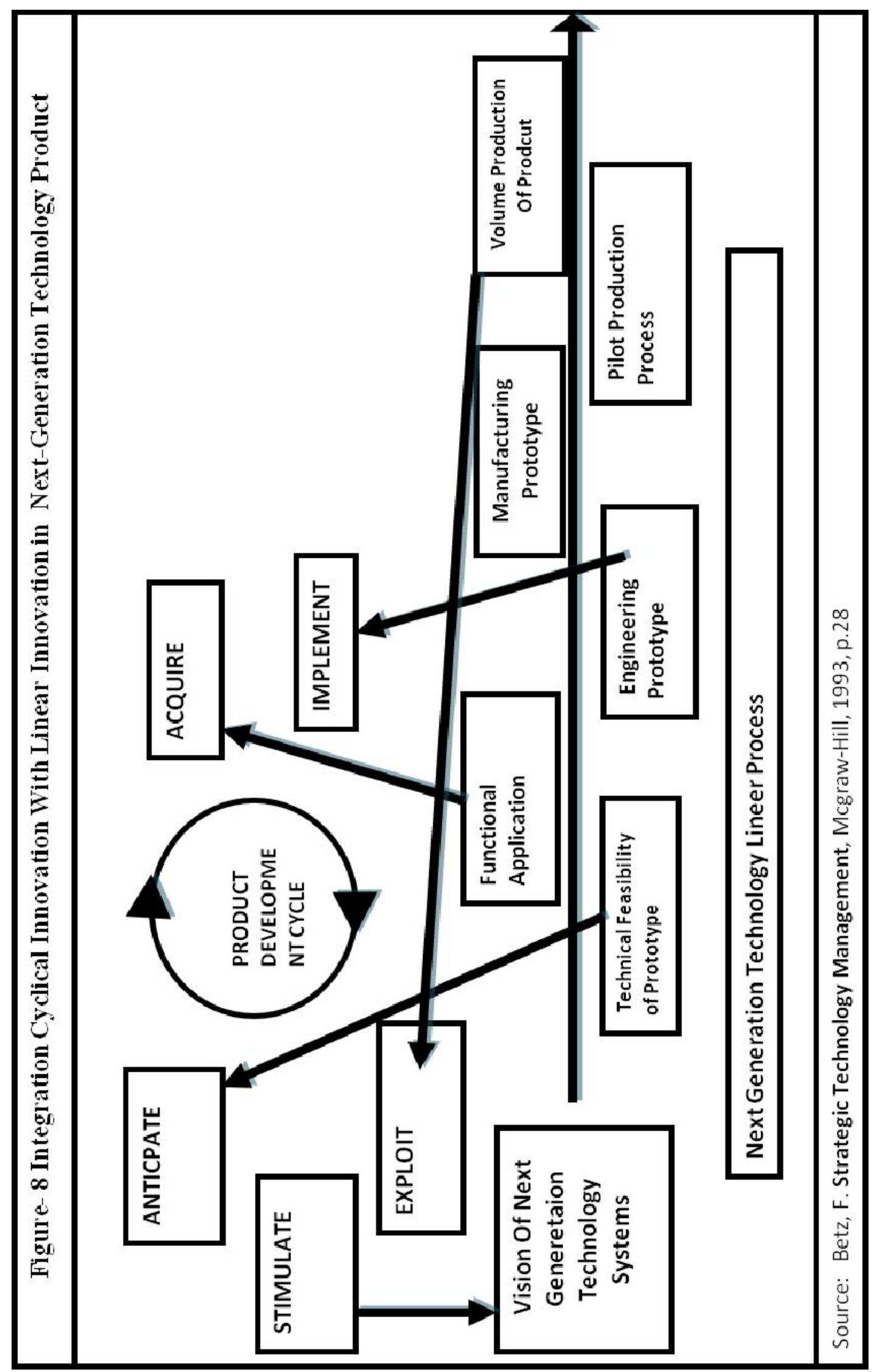


Narayanan (2001:255) stated that specific technology choices exhibit a pattern over time, these patterns may be classified two dimensions, scope and leadership. Based on the two dimensions four broad types of technology strategies are available. These are as follows (see in Table-4):

Technology leadership strategy consist of establishing and maintaining through both technology development and deployment of a preeminent position in the competitive domain in all the technologies for a dominant market position. Technology is the primary instrument for creating and maintaining competitive advantage for these firms.

Niche strategy consists of focusing on a limited number of critical technologies to seek leadership. Technology development is selective, and deployment is oriented toward exploiting the technological strength of the firm in selected technologies to create competitive advantage.

Follower strategy consists of maintaining technological adequacy in a broad set of technologies. This strategy is focused on deployment, avoiding the risks of basic research. For these firms, technology is not their primary instrument for seeking competitive advantage.

Technology rationalization involves maintaining adequacy only in a select set of technologies. For these firms, their technology deficit should be compensated by other competitive strenghts in order for them to survive in many competitive domains.

Liu, Ju , Baskaran, A. Li, S. (2009) found that the firm's technological-innovation-based strategic capabilities were neither influenced by technological resources, nor by innovation resources, but by organizational culture, human resources and organizational structure, among which human resources is the most dynamic one. For firms with ambition to maintain a high level of strategic capabilities it is imperative that they develop and enhance their organizational culture in a flexible organizational environment. For firms with the objective of transforming or transplanting their existing capabilities, it is likely to be effective if they change or transfer the human resources, respectively.

Table- 4 Technology Strategy Types

\begin{tabular}{|c|c|c|c|}
\hline & \multicolumn{2}{|c|}{ Scope } \\
\hline & & Full & Selective \\
\hline \multirow[b]{2}{*}{ Leadership } & Leadership & $\begin{array}{c}\text { Full Line } \\
\text { Technology } \\
\text { Leader }\end{array}$ & $\begin{array}{l}\text { Niche } \\
\text { Player }\end{array}$ \\
\hline & Followership & $\begin{array}{c}\text { Technology } \\
\text { Follower }\end{array}$ & $\begin{array}{l}\text { Technology } \\
\text { Rationalizer }\end{array}$ \\
\hline \multicolumn{4}{|c|}{$\begin{array}{l}\text { Source: Little, A.D. "The Strategic Management Of Technology" Cited In Narayanan, V.K. } \\
\text { Management Technology And Innovation For Competitive Advantage, Prentice Hal, USA, } \\
\text { 2001, p.255 }\end{array}$} \\
\hline
\end{tabular}

Schilling (2008) stated that it is useful to begin with some standard tools of strategic analysis for analyzing the external and internal environment of the firm to assess the firm's current position in the marketplace. Figure-9 shows the environmental competition model of the firm developed by Michael Porter (1980) called Porter's Five-Force Model. The model points out the attractiveness of the industry and the threats and opportunities for the firms in the industry. Firms analyse the industrial competition conditions via this model when applying technological innovation strategies. 


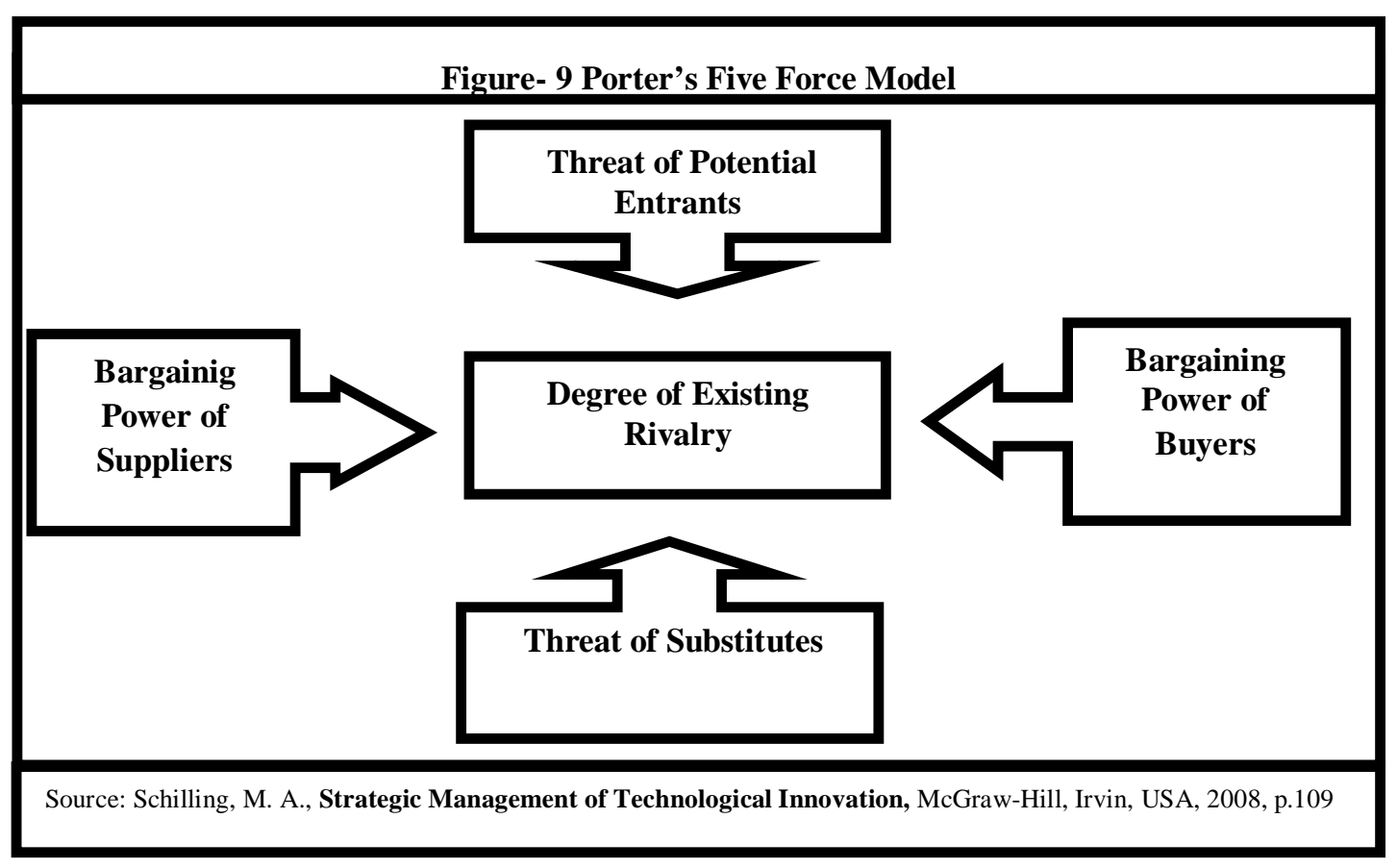

Schilling (2008) also emphasized those stakeholders' models which are used to strategic and normative analysis. A strategic stakeholder analysis emphasizes the stakeholder management issues that are likely to impact the firm's financial performance, while a normative stakeholder analysis emphasizes the stakeholder management issues that the firm ought to attend due to their ethical or moral implications. Stakeholders include stockholders, employees, customers, suppliers, lenders, the local community, government, and rivals. Another analysis of the firm's strategic decisions is the internal analysis developed by Porter (1985) which begins with identifying the firms' strength and weakness and examines each activity of the value chain in the firm.

Narayanan (2001:256) stated that the various strategy types are appropriate for different strategic contexts, characterized by the stages in technological evolution of competitive domains and the strategic positions of firms. The era of technology and innovation structures affects the appropriateness of the technology strategy. Table-5 demonstrates the appropriateness of technology strategy. In the era of incremental innovation, technology leadership strategy is appropriate for firms that have strong technological and market positions. Niche strategy is recommended for technologically strong but competitively moderate positions. Technology followership requires a strong competitive position in the markets, although the firm may lack technological superiority. If the firm is competitively weak, then it may be forced to adopt a technology rationalization strategy. In the era of technology emergence, the leader strategy is much more broadly applicable, because the technologies and markets tend to be highly fluid. Thus, there are more opportunities to gain competitive advantage.

Damanpour and Grevesen, (2007) stated that Multinational Enterprises (MNEs) are uniquely equipped to acquire knowledge from external sources because they can access pockets of innovation located throughout the world. MNEs can source knowledge externally through foreign direct investment in $R \& D$-a strategy that has become prevalent during the past two decades.- Unfortunately, little is known about the performance implications of external knowledge sourcing through $R \& D$ internationalisation, nor have researchers determined how organisational structure and intrafirm knowledge-sharing routines affect innovative performance in multinationals that set up $R \& D$ sites abroad. Damanpour and Grevesen, (2007) examined the effect of organisational structure and knowl- 
edge sharing on innovative performance in the overseas R\&D units of North American, European and Japanese multinationals. An analysis of data from a survey of overseas R\&D site directors in 17 countries suggests that innovative performance is enhanced by the lateral and hierarchical exchange of knowledge but suppressed by bureaucratic coordination and control mechanisms.

Betz (1993:28) stated that formulating technology strategy requires methods for bringing the technical and other business-functional personnel together to manage both incremental and radical innovation.

1-A vision of a next-generation technological system and the planning of the directions and nature of research programs to generate the advanced ideas for that system.

2-An understanding of the business opportunities and competitive advantages of the new technology.

3-Management of the scientific and engineering activities that create new technology.

4-Transfer of the new technology into product design and production-process design and improvement.

Damanpour and Wischnevsky,(2009) stated that over time, firms tend to develop relatively stable strategies and organisational arrangements. Radical departure from such patterns is infrequent, yet sometimes necessary for organisational effectiveness and survival. Damanpour and Wischnevsky, (2009 examined key factors that facilitate radical strategic and structural change and the performance consequences associated with each type of change. Our analysis of a sample of bank holding companies in the USA over 20 years suggests that radical structural change occurs more frequently than radical strategic change and that radical strategic change positively influences the likelihood that radical structural change will follow, but not the reverse. Results also show that sustained low performance and top executive change facilitate the occurrence of radical strategic but not structural change and that neither type of change exhibits a significant effect on firm profitability and survival.

Table- 5 Appopria Tennes of Technology Stategy

\begin{tabular}{|c|c|c|c|c|c|c|c|}
\hline \multirow{5}{*}{ 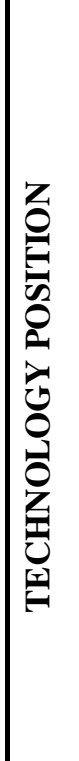 } & \multicolumn{3}{|c|}{$\begin{array}{l}\text { ERA OF TECHNOLOGY } \\
\text { EMERGENCE }\end{array}$} & \multirow{2}{*}{ 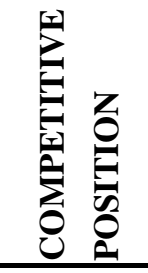 } & \multicolumn{3}{|c|}{$\begin{array}{c}\text { LATE STAGES OF } \\
\text { INCREMENTAL CHANGE }\end{array}$} \\
\hline & Strong & Medium & Weak & & Strong & Medium & Weak \\
\hline & Leader & Leader & Follower & Strong & Leader & Follower & Acquisition \\
\hline & Leader & $\begin{array}{c}\text { Follower } \\
\text { Niche }\end{array}$ & Acquisition & Medium & Niche & $\begin{array}{c}\text { Follower } \\
\text { Rational- } \\
\text { ization } \\
\end{array}$ & $\begin{array}{l}\text { Rational- } \\
\text { ization }\end{array}$ \\
\hline & Niche & $\begin{array}{c}\text { Joint } \\
\text { Venture }\end{array}$ & $\begin{array}{l}\text { Rational- } \\
\text { ization }\end{array}$ & Weak & $\begin{array}{c}\text { Joint } \\
\text { Venture }\end{array}$ & $\begin{array}{c}\text { Rational- } \\
\text { ization }\end{array}$ & Divestment \\
\hline
\end{tabular}




\section{CONCLUSION}

As the technological innovation is a very important factor for the firms in order to increase competitiveness and profitability in a competitive global economy conditions, firms have to manage technological innovation successfully by considering both internal and external factors to the firm. Firms develop technological innovations not only applying new-product development strategies but also by applying market-oriented competitive strategies.

Firms should optimize their technological innovation management strategy by analysing the changing technological dynamics, on the one hand, the changing needs of the market, society and consumers, on the other hand, and fnally changing scientific and technological developments. Firms should design technological innovation environment in the firm level to increase technological innovations which lead to competitiveness of the firm by organizing human resources, $R \& D$, technology and innovation management policies and strategies.

As long as firms successfully manage technological innovations, respectively their competitiveness, market value and profitability increase. For this reason, it is very important for firms to develop and apply optimal technology and innovation strategies to increase their competitiveness. 


\section{REFERENCES}

Annavarjula, M. And Mohan, R. (2009) "Impact of Technological Innovation Capabilities on the Market Value of Firms." Journal of Information \& Knowledge Management; Vol. 8 Issue 3, p241250, 10p, 6 charts

Betz, F.(1993) Strategic Technology Management, Mcgraw-Hill,

Damanpour, Fariborz ,Grevesen, Chris W. (2007) "Performance Implications Of Organisational Structure And Knowledge Sharing In Multinational R\&D Networks." International Journal of Technology Management; Vol. 38 Issue 1/2, p113-136, 14p,

Damanpour, Fariborz, Wischnevsky, J. Daniel, (2008) "Radical Strategic And Structural Change: Occurrence, Antecedents and Consequences" International Journal of Technology Management; Vol. 44 Issue 1/2, p53-80, 28p

Damanpour, F., Bierly, Paul E. and Santoro, Michael D. (2009) "The Application of External Knowledge: Organizational Conditions for Exploration and Exploitation" Journal of Management Studies 46:3 May

Edquist, Charles And Leif Hommen, (1999) "Systems Of Innovation: Theory And Policy The Demand Side" Technology In Society 21 63-79

Fariborz, D.Richard M. W, Claudia N.A. (2009) "Combinative Effects of Innovation Types and Organizational Performance: A Longitudinal Study of Service" Organizations Journal of Management Studies 46:4 June

Galende A, Jesús, Juan Manuel De La Fuente, (2003) “Internal Factors Determining A Firm’s Innovative Behaviour" Research Policy 32 715-736

Hannay, N. Bruce., (1980), "Technological Innovation: Its Nature and Significance” Bulletin of the American Academy of Arts and Sciences, Vol. 33, No. 6, pp. 34-48

Huergo, Elena. (2006) "The Role Of Technological Management As A Source Of Innovation: Evidence From Spanish Manufacturing Firms”, Research Policy 351377

Knight, Kenneth E. (1967), "A Descriptive Model of the Intra-Firm Innovation Process" The Journal of Business, Vol. 40, No. 4. pp. 478-496.

Lıu, Ju , Baskaran, A. L1, S. (2009) "Building Technological-Innovation-Based Strategic Capabilities at Firm Level in China: A Dynamic Resource-Based-View Case Study.” Source:Industry \& Innovation; Vol. 16 Issue 4/5, p411-434, 24p

Little, A.D. The Strategic Management Of Technology, 1981, European Management Forum, in Narayanan, V.K. Management Technology And Innovation For Competitive Advantage, Prentice Hal, USA, 2001, p.256

Narayanan, V.K. (2001) Management Technology And Innovation For Competitive Advantage, Prentice Hal, Usa

OECD And Eurostat, (2005) Oslo Manual Guidelines For Collecting And Interpreting Innovation Data, Third Edition, A Joint Publication Of Oecd And Eurostat, 
Journal of Global Strategic Management | V. 3 | N. 2 | 2009-June | isma.info | 209-226 | DOI: 10.20460/JGSM.2009318470

OECD,(1997) The Measurement Of Scientific And Technological Activates Proposed Guidelines For Collecting And Interpreting Technological Innovation Data, Oslo Manual, 2nd Edition.

Porter, M.E. (1980) Competitive Strategy, Newyork: Free Press, New York,

Schilling, M. A., (2008) Strategic Management Of Technological Innovation, Mcgraw-Hill, Irvin, Usa, 2008,

Utterback, James M. (1971), "The Process of Technological Innovation within the Firm” The Academy of Management Journal, Vol. 14, No. 1 pp. 75-88 